Check for updates

Cite this: RSC Adv., 2019, 9, 14503

\title{
Oxidation behavior of the TiAIN hard coating in the process of recycling coated hardmetal scrap
}

\begin{abstract}
Hai Kuang, ${ }^{\text {ab }}$ Dunqiang Tan, (D) *a Wen He, ${ }^{a}$ Zhiqiang $\mathrm{Yi}^{\mathrm{a}}{ }^{\mathrm{F}}$ Fan Yuan ${ }^{\mathrm{a}}$ and Yukun $\mathrm{Xu}^{\mathrm{a}}$
Recycling coated hardmetal scraps is becoming increasingly important for tungsten resource recovery. However, the coatings in these materials are one of the biggest problems, especially Al-containing coatings. In this study, discarded TiAIN-coated WC-Co hardmetal tool tips were isothermally oxidized at $900{ }^{\circ} \mathrm{C}$ in air, during which the final oxide, phase transition and microstructure evolution were investigated. Milled powders below $0.15 \mathrm{~mm}$ were completely oxidized in $180 \mathrm{~min}$, and pieces of coatings were found in the final oxides. White $\mathrm{WO}_{3}$ was mainly distributed on defect-rich areas of oxide scale surfaces. Furthermore, the final oxide scale was triple-layered, mainly consisting of the $\mathrm{WO}_{3}-$ concentrated outmost layer, the $\mathrm{Al}_{2} \mathrm{O}_{3}$-concentrated middle layer, and the $\mathrm{TiO}_{2}$-concentrated inner layer. It is different from the bi-layered $\mathrm{Al}_{2} \mathrm{O}_{3} / \mathrm{TiO}_{2}$ oxide scale that appeared for a new TiAIN-coated hardmetal during an oxidation resistance test. This was attributed to the defects in hardmetal scraps, which provided a fast pathway for element diffusion and volatilization of $\mathrm{WO}_{3}$. Consequently, it was impossible to remove $\mathrm{Al}_{2} \mathrm{O}_{3}$ completely.
\end{abstract}

Received 31st October 2018

Accepted 18th April 2019

DOI: 10.1039/c8ra09013k

rsc.li/rsc-advances

hardmetal tool tips with titanium carbonitride (TiCN)/

\section{Introduction}

Tungsten is an essential strategic metal that is widely applied due to its high hardness, density, and melting point. However, tungsten is limited as a resource and will be exhausted within the next 40 years, ${ }^{1}$ and therefore, its recovery is urgent. An increasingly important source is the recycling of tungstenbased cemented carbide scraps, ${ }^{2}$ which comprise at least $75 \mathrm{wt} \%$ tungsten carbide. ${ }^{3}$ Furthermore, recycling is environmentally friendly and low cost compared to mineral-based production. Nevertheless, only uncoated cemented carbide scraps were favored for recycling; the majority of coated ones were unpopular due to the big problem of coating. Additional coating elements and complicated structures influence the recycling process, making it different from common methods. Furthermore, some coating elements remain in recycled products, thereby degrading the performance of reclaimed hardmetals. ${ }^{4}$

In recent years, the increasing demand for tungsten, the decreasing tungsten resource, and the increasing price of uncoated hardmetal scraps have resulted in increased focus on recycling coated cemented carbide scraps. Sunjung Kim ${ }^{5,6}$ recycled the CrAlN-coated WC-Co inserts via oxidation and wet milling. However, this process required corrosive sulfuric acid solution, which is harmful to health. We have previously reported the use of the zinc process for recycling WC-Co

${ }^{a}$ School of Materials Science and Engineering, Nanchang University, Nanchang 330031, China.E-mail: tdunqiang@ncu.edu.cn

${ }^{b} J$ iangxi Science and Technology Normal University, Nanchang 330038, China aluminum oxide $\left(\mathrm{Al}_{2} \mathrm{O}_{3}\right) /$ titanium nitride (TiN) coatings. ${ }^{7}$ The result revealed that pieces of $\mathrm{Al}_{2} \mathrm{O}_{3}$ coatings were found in reclaimed WC powders. It is clear that $\mathrm{Al}_{2} \mathrm{O}_{3}$ is well known for its excellent stability, and it is therefore not easily attacked by other chemicals or decomposed. Consequently, $\mathrm{Al}_{2} \mathrm{O}_{3}$ represents a defect in recycled hard alloys, decreasing hardness and relative density. Therefore, $\mathrm{Al}_{2} \mathrm{O}_{3}$ - either itself or coating production-is one of the biggest problems for coated hardmetal scraps' recycling. It has been previously demonstrated that titanium aluminum nitride (TiAlN) hard coating is widely used in cutting tool tips for its superior oxidation resistance, as the protective dense $\mathrm{Al}_{2} \mathrm{O}_{3}$ top layer can be formed on at high temperatures..$^{8-14}$ Therefore, TiAlN coatings are not favored for recycling of cemented carbide scraps. On the other hand, widespread application and increasing requirements have resulted in a great number of discarded TiAlN coated hardmetals, which is a huge waste of tungsten resources, and thus recycling them for tungsten is essential. However, reducing the negative effects of $\mathrm{Al}_{2} \mathrm{O}_{3}$ represents one of the biggest challenges. Our previous report ${ }^{15}$ revealed that the negative effect was reduced when $\mathrm{Al}$ was transformed to $\mathrm{Al}_{4} \mathrm{C}_{3}$ after oxidation, reduction, and carbonization processes. Therefore, the oxidation and reduction-carbon process is supposedly a good choice for recycling hardmetal scraps covered with TiAlN hard coating, where no corrosive chemicals were required. Oxidation is a crucial first step of the process. The oxidation evolution of TiAlN coatings and how Al exists in recycled oxide greatly influence the following two processes, and the final resultant recycled cemented carbides. Many 
defects were present after the repetitive cutting operation, ${ }^{\mathbf{1 6}}$ which differs from the normal oxidation resistance test for the new coating. However, a limited number of studies have aimed to understand oxidation behaviors and mechanisms of worn TiAlN hard coating during hardmetal scraps' recycling by the oxidation and reduction-carbonization process.

In this paper, the isothermal oxidation behavior of discarded WC-Co hardmetal inserts covered with a TiAlN hard coating was investigated, focusing on the oxidation kinetics, phase transformation, and the evolution of TiAlN hard coating.

\section{Materials and methods}

\subsection{Materials}

WC-Co cutting tool tips were used as raw material when they were useless for cutting metals. The weight of every insert was about $7 \mathrm{~g}$. A violet-grey nc-TiAlN hard coating was deposited on the surface using the physical vapor deposition (PVD) method (Fig. 1). The SEM image in Fig. 1c depicts the coating's thickness $(\sim 2 \mu \mathrm{m})$. Coatings were locally lost on edges and corners due to the repeated cutting operations.

\subsection{Experimental procedures}

Fig. 2 shows the oxidation and reduction-carbon process for recycling hardmetal scraps. ${ }^{17}$ In this paper, worn coated cemented carbides were ultrasonically cleaned with acetone, deionized water, and ethanol for $15 \mathrm{~min}$, consecutively. Cleaned insert tips were then placed into drying oven (DZG-6050, Senxin, Shanghai, China) at $100{ }^{\circ} \mathrm{C}$ for $1 \mathrm{~h}$. Some dried inserts were subsequently broken into pieces or milled into powders

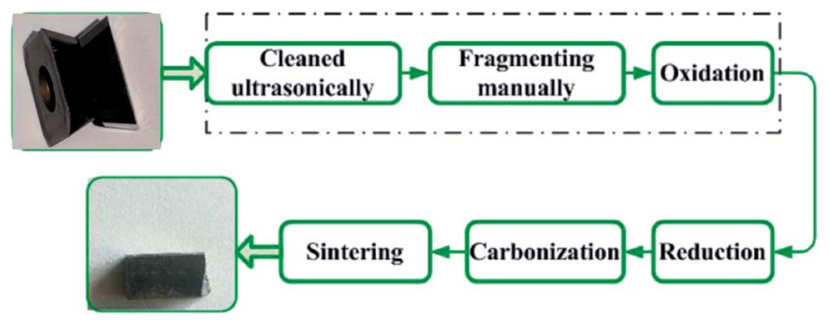

Fig. 2 Recycling waste inserts by the oxidation and reduction-carbon process.

manually. Powders were passed through a 100 mesh sieve and particle size was below $0.15 \mathrm{~mm}$. Untreated inserts, fragments and powders of the same weight were put in to rectangular alumina crucibles, then isothermally maintained in ambient air at $900{ }^{\circ} \mathrm{C}$ after heating from room temperature in an electrical resistance furnace (SX2-4-10, Yifeng, Shanghai, China) for 10, 30, 60, 120, and $180 \mathrm{~min}$. Further oxidation time for the whole inserts was prolonged to $240 \mathrm{~min}$ for complete oxidation.

Chemical phases were examined by X-ray diffraction (XRD, PANalytical, EMPYREAN, Netherlands) in the Bragg-Brentano geometry with $\mathrm{Cu}-\mathrm{K} \alpha$ radiation $(\lambda=0.154 \mathrm{~nm})$ using the continuous scanning mode in $2 \theta$ ranging from $10^{\circ}$ to $90^{\circ}$. XRD patterns were acquired with a step size of $0.01^{\circ}$ and a speed of $2^{\circ} \min ^{-1}$. The voltage was $40 \mathrm{kV}$ and current was $40 \mathrm{~mA}$. Backscattered electron (BSE) morphologies of samples were observed under vacuum using field emission scanning electron microscope (FESEM, Nova NanoSEM450, FEI, USA), with $20 \mathrm{kV}$ working voltage. The elements' distribution was characterized by energy-dispersive X-ray spectroscopy (EDS, X-max 80, Oxford Instruments, UK). Al concentration was tested using an
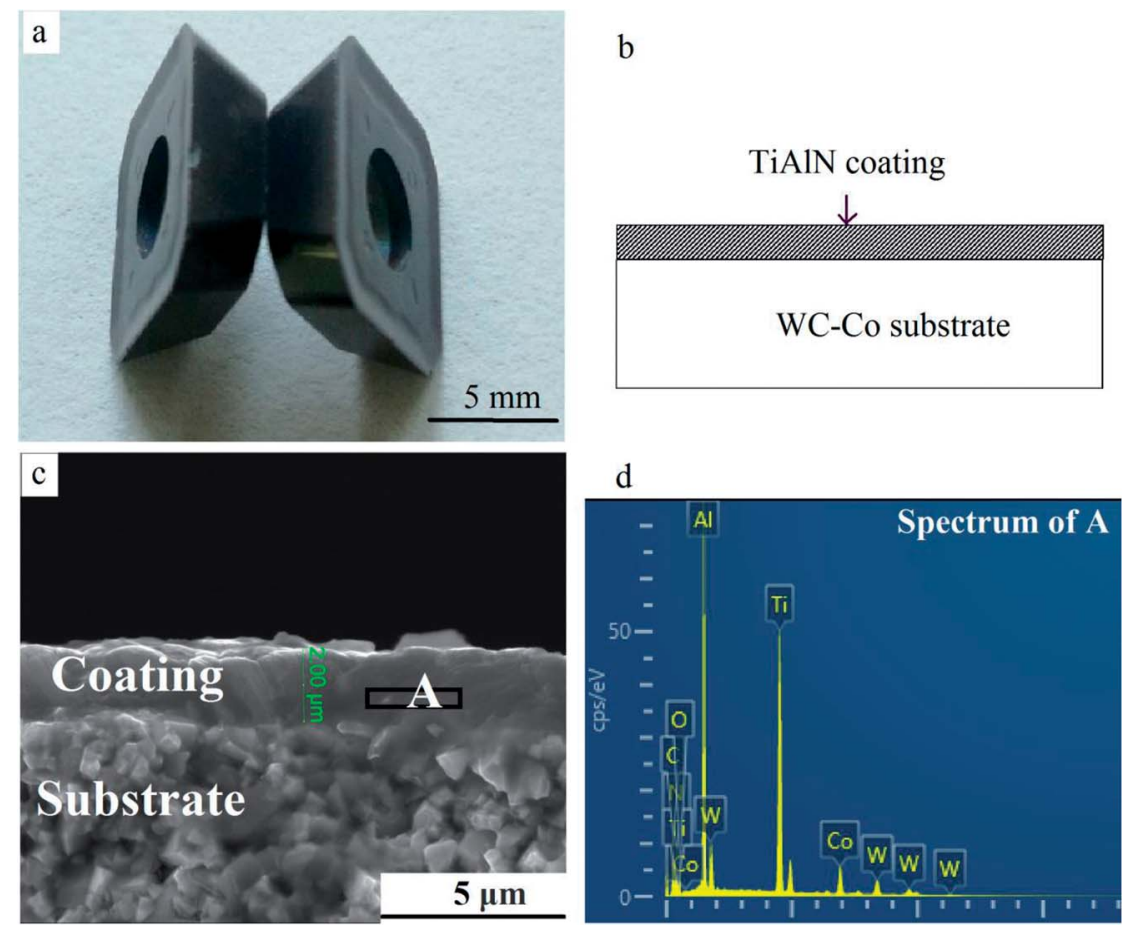

\section{$\mathrm{d}$}



Fig. 1 TiAIN hard coating on WC-Co substrates. (a) Macrograph, (b) schematic, (c) cross-sectional SEM image, and (d) the EDS result of area A. 
inductively coupled plasma optical emission spectrometer (ICPOES, optima 8000, PerkinElmer, USA) with an accuracy of $0.005 \mathrm{mg} \mathrm{L}{ }^{-1}$. Weights were measured using an electronic balance (lucky, Wuxin) with $0.001 \mathrm{~g}$ accuracy.

\section{Results and discussion}

\subsection{Oxidation kinetics}

Coated hardmetal scraps were oxidized at $900{ }^{\circ} \mathrm{C}$, according to previously published methods,${ }^{5,18}$ which was demonstrated in our previous work. ${ }^{17}$ Fig. 3 illustrates time dependence of the weight ratio $\left(W / W_{0}\right)$ when samples were oxidized at $900{ }^{\circ} \mathrm{C}$. $W$ was

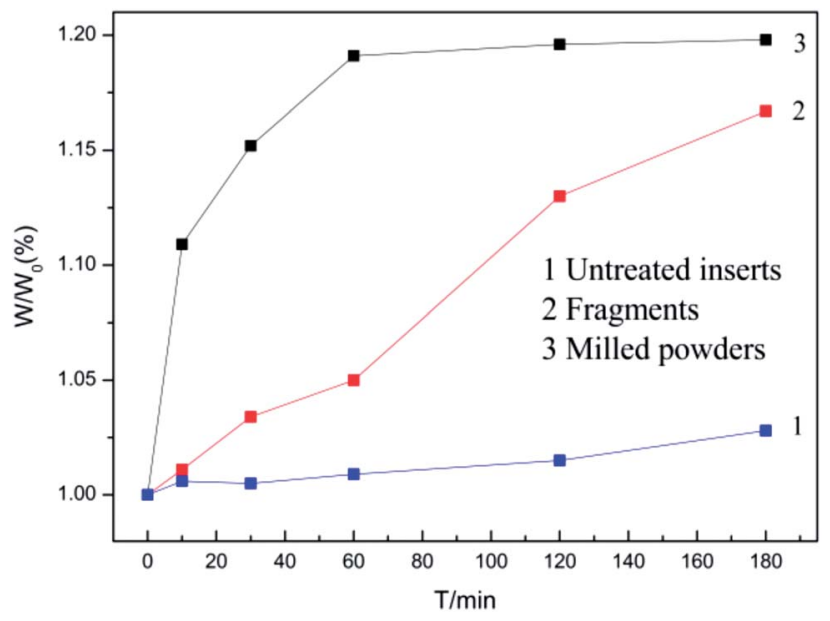

Fig. 3 Weight ratios versus oxidation time. the oxidation weight and $W_{0}$ was the weight before oxidation. As shown in Fig. 3, the weight ratio for untreated inserts increased slowly due to the protective coating. For fragments, the weight ratio increased faster as more WC-Co surfaces were exposed to air, but the value only reached about 1.16 when oxidized for $180 \mathrm{~min}$. The coated hardmetal tool tips were milled into powders to accelerate the oxidation process. Fig. 3 illustrates that the weight ratio for powdered samples exhibited parabolic-like behavior. The weight ratio increased rapidly before $60 \mathrm{~min}$. As oxidation continued for $180 \mathrm{~min}$, the weight ratio was $\sim 1.19$, which was almost reached the maximum relative weight gain when fully oxidized. ${ }^{19}$ These data indicate that total oxides can be obtained when powdered samples with particle size below $0.15 \mathrm{~mm}$ are oxidized in air at $900{ }^{\circ} \mathrm{C}$ for $180 \mathrm{~min}$.

Fig. 4 presents macrographs in the oxidation process. Fig. 4a shows milled powders at different oxidation times. Many black WC particles are clearly visible when oxidized for 10 and $30 \mathrm{~min}$. After oxidation for $60 \mathrm{~min}$, only a few black WC particles were visible, as they were either oxidized or wrapped in oxides. These results were complementary to those in Fig. 3, where the weight ratio was $\sim 1.18$ at that time. ${ }^{19}$ Powders became completely bluish-gray upon further oxidation for $180 \mathrm{~min}$. According to the result in Fig. 3, they were fully oxidized.

Coatings were too small and difficult to find in powdered samples sieved through a 100 mesh screen. In order to study the oxidation behavior of TiAlN hard coating in detail, unfragmented inserts and fragments were oxidized under the same conditions. As shown in Fig. 4b, surface color visibly changed. The coating was violet-grey before oxidation, changed to bright
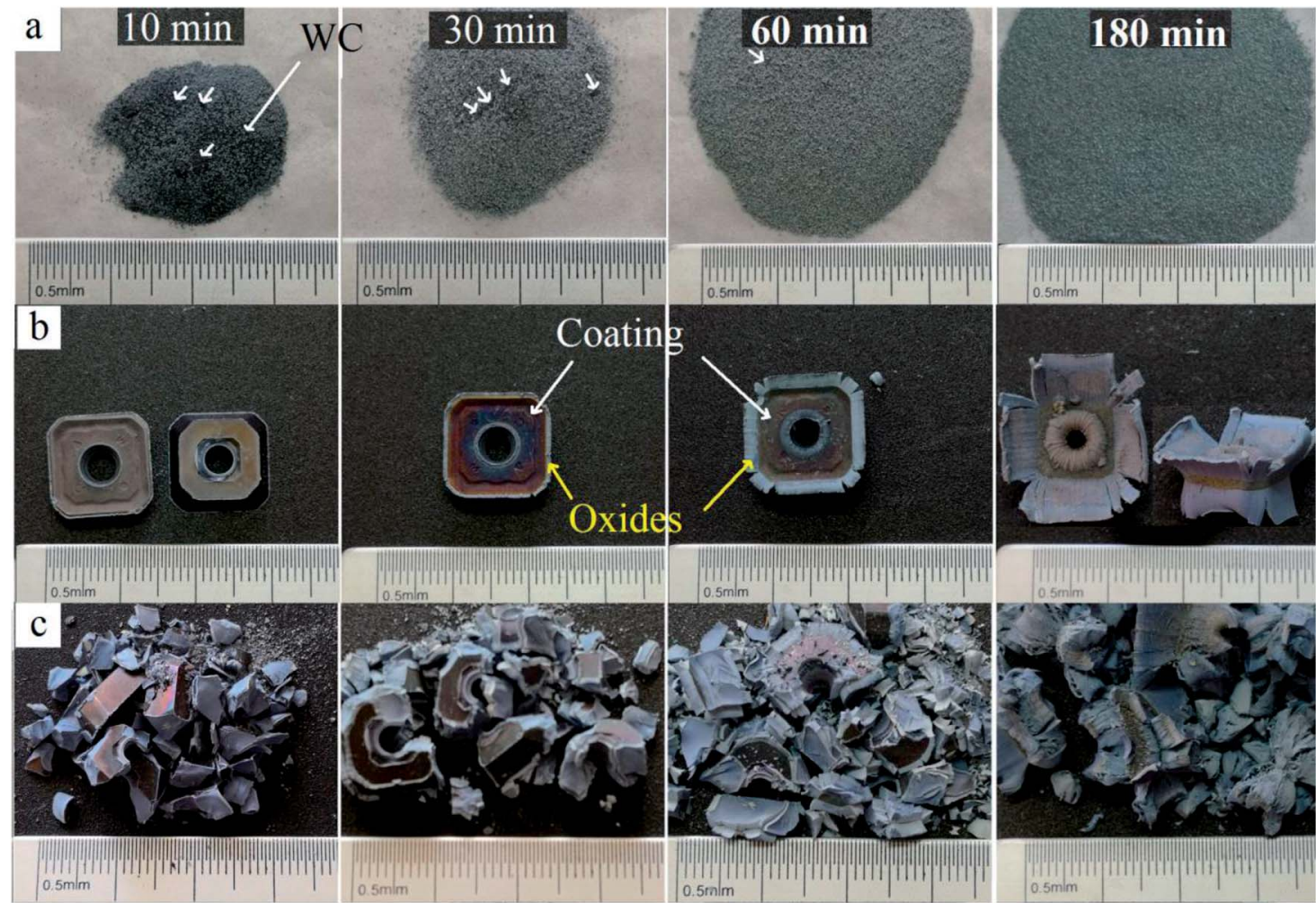

Fig. 4 Macrographs of samples in the oxidation process. (a) Milled powders, (b) whole inserts, and (c) fragments. 

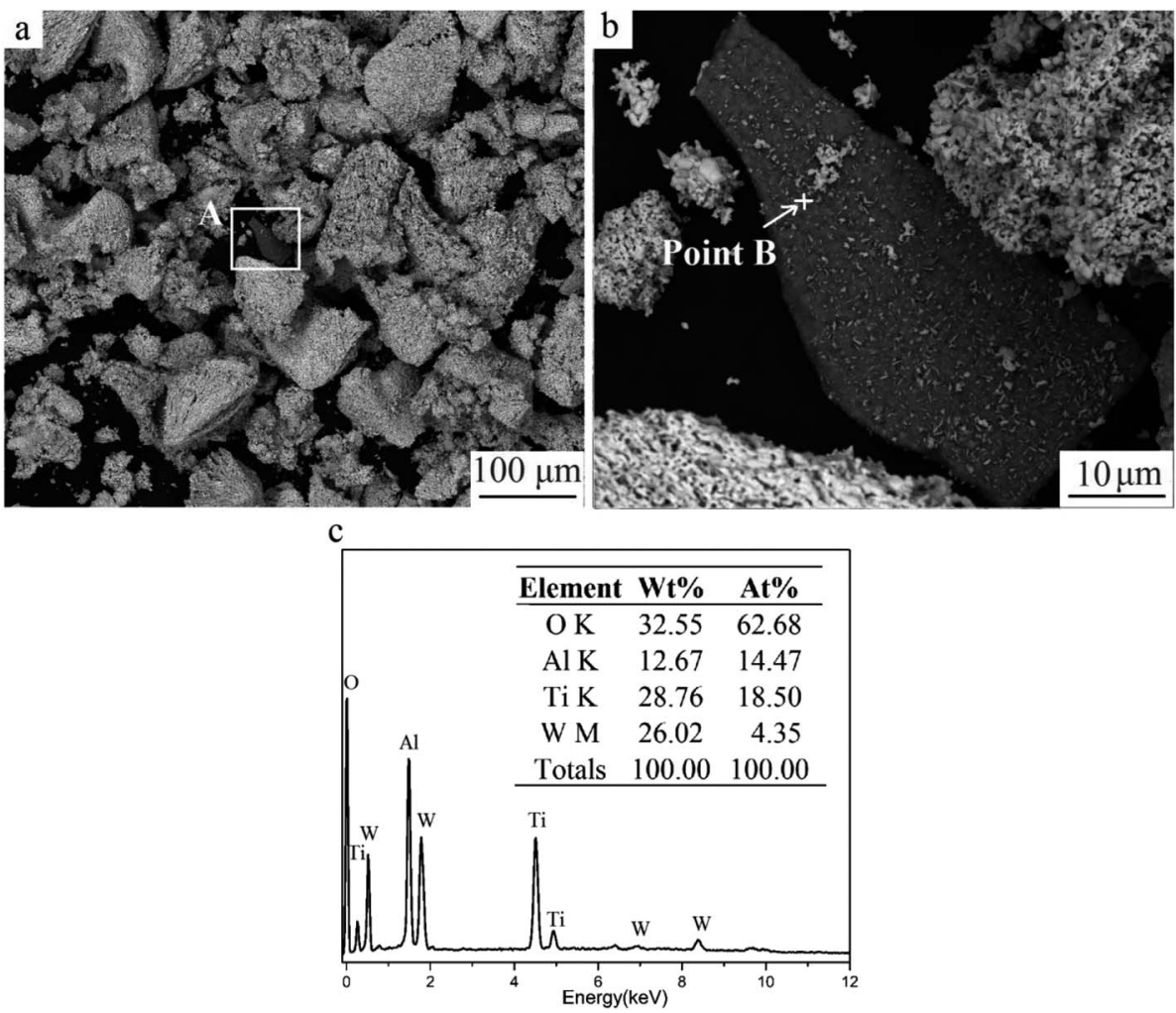

Fig. 5 Milled powders oxidized for 180 min. (a) SEM image, (b) magnified image of area A, and (c) the EDS result of point B.

purple, gray and yellowish-gray when oxidized for 30,60 , and $180 \mathrm{~min}$, respectively. This demonstrated phase transition during the oxidation process. Surface color on fragments changed more rapidly (Fig. 4c), indicating a faster oxidation rate. The result revealed that the oxidation rate of milled powders was the most rapid and the slowest of unfragmented inserts. The main reason being that the protective coating inhibited element diffusion. It is proposed that coated hardmetal scraps can be milled into powders before being recycled by the oxidation and reduction-carbon process for accelerating the recycling process.

\subsection{Coatings in the oxide powders}

Fig. 5 shows the oxide obtained when milled powders were oxidized for $180 \mathrm{~min}$. The black fragment (area A) was seen clearly among white particles. The EDS result displayed that $\mathrm{O}$,
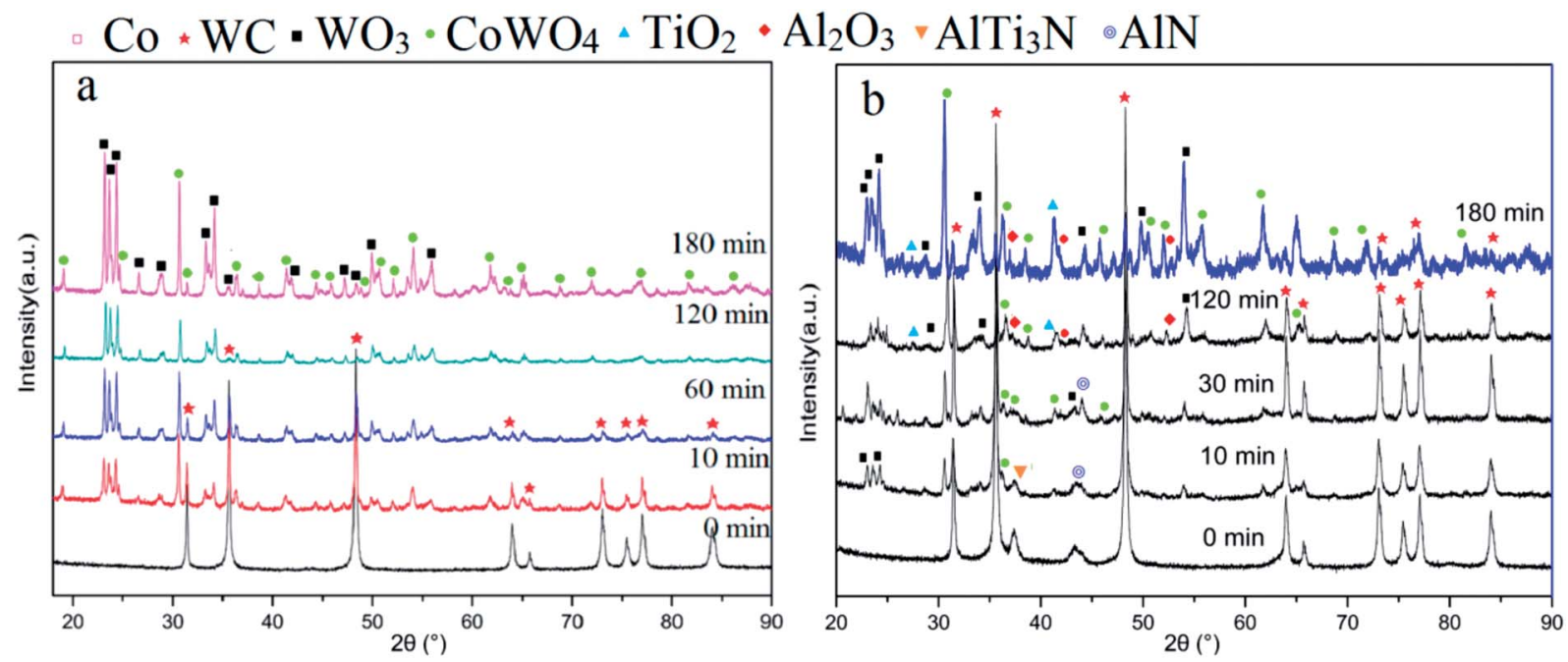

Fig. 6 XRD patterns of samples at different oxidation times for (a) milled powders, (b) surface of whole inserts. 

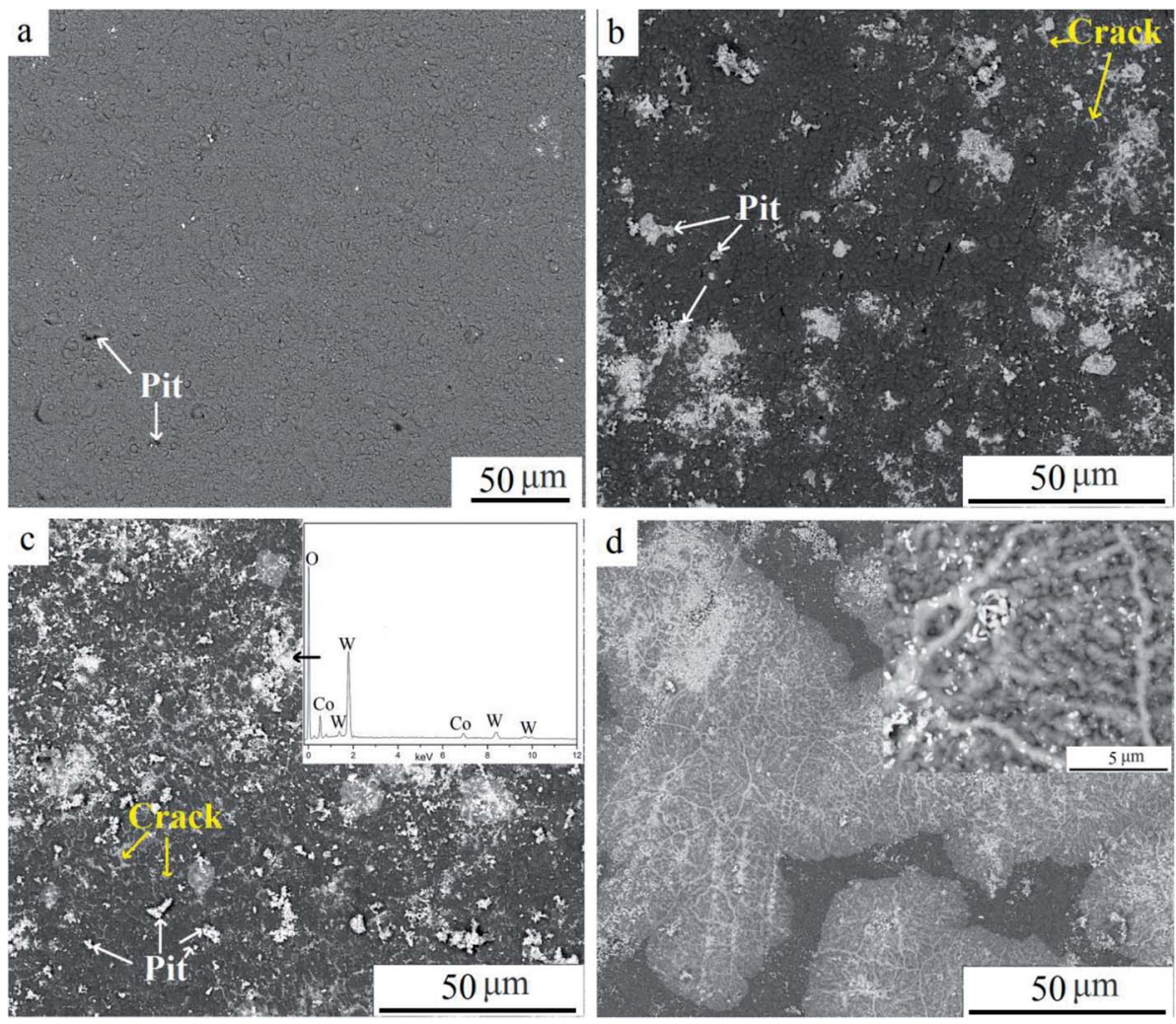

Fig. 7 SEM surface images of samples at various oxidation times: (a) $0 \mathrm{~min}$, (b) $10 \mathrm{~min}$, (c) $30 \mathrm{~min}$, and (d) $120 \mathrm{~min}$.

$\mathrm{Ti}$, and $\mathrm{Al}$ elements were found at point $\mathrm{B}$. The high $\mathrm{O}$ and nonexistence $\mathrm{N}$ content demonstrated that TiAlN were transformed to mixed oxides containing $\mathrm{Ti}$ and $\mathrm{Al}$. The concentration of $\mathrm{Al}$ was $228 \mathrm{mg} \mathrm{kg}^{-1}$, tested by ICP-OES. Therefore, Al-containing coating was retained in final oxide powders, which would influence the downstream recycling process and recycled products.

\subsection{Phase transitions}

Fig. 6 shows that the phases changed with increasing oxidation time. Fig. 6a depicts the XRD results of milled powders below $0.15 \mathrm{~mm}$. Peaks of $\mathrm{CoWO}_{4}$ and $\mathrm{WO}_{3}$ can be found when a number of WC-Co surfaces are oxidized for $10 \mathrm{~min}$. The number of peaks of $\mathrm{CoWO}_{4}$ and $\mathrm{WO}_{3}$ increased upon further oxidation, while the number of WC peaks decreased. After oxidation for $180 \mathrm{~min}$, no WC peak was present, while $\mathrm{CoWO}_{4}$ and $\mathrm{WO}_{3}$ remained. It can be described by the following reactions. ${ }^{19,20}$

$$
\begin{gathered}
\mathrm{WC}+\frac{5}{2} \mathrm{O}_{2} \rightarrow \mathrm{WO}_{3}+\mathrm{CO}_{2} \uparrow \\
\mathrm{WC}+2 \mathrm{O}_{2} \rightarrow \mathrm{WO}_{3}+\mathrm{CO} \uparrow \\
\mathrm{Co}+\mathrm{WC}+3 \mathrm{O}_{2} \rightarrow \mathrm{CoWO}_{4}+\mathrm{CO}_{2} \uparrow
\end{gathered}
$$

At $900{ }^{\circ} \mathrm{C}$, the Gibbs free energy of the above reactions (eqn (1)-(3)) at one atmospheric pressure were approximately -930 $\mathrm{kJ},-750 \mathrm{~kJ}$, and $-1117 \mathrm{~kJ}$, respectively, according to the reported thermodynamic calculations., ${ }^{5,6,18}$ They were all below zero, indicating that the above three reactions take place when oxidized under 1 atmospheric pressure at $900{ }^{\circ} \mathrm{C}$. The XRD patterns indicated that the oxidation process can be finished in 180 min for TiAlN coated WC-Co hardmetal powders. The final oxide was mixed with $\mathrm{WO}_{3}$ and $\mathrm{CoWO}_{4}$, which coincided with the results in Fig. 3 and 5. In addition, Al-containing phases were not detected due to their weak signals or they were hidden by the XRD pattern noise.

In order to study the detailed phase evolution of TiAlN coatings, Fig. 6b shows the XRD result for surfaces on whole inserts at different oxidation times. After oxidation for $10 \mathrm{~min}$, peaks of $\mathrm{WO}_{3}$ and $\mathrm{CoWO}_{4}$ from substrate oxides appeared, as the thickness of TiAlN coating in raw material was only $\sim 2 \mu \mathrm{m}$. The peak of $\mathrm{AlTi}_{3} \mathrm{~N}$ and AlN from the TiAlN coating were retained. When oxidized for $30 \mathrm{~min}$, more $\mathrm{WO}_{3}$ and $\mathrm{CoWO}_{4}$ peaks appeared, and the AlN peak was still visible. It has been reported that $\mathrm{AlTi}_{3} \mathrm{~N}$ was decomposed to TiN and AlN. ${ }^{13}$ TiNrelated products cannot be detected due to their limited content. With further oxidation for $120 \mathrm{~min}$, peaks of $\mathrm{Al}_{2} \mathrm{O}_{3}$ and $\mathrm{TiO}_{2}$ appeared, which were oxides of TiAlN coatings. ${ }^{\mathbf{1 0}, 14}$ This is in good agreement with EDS result shown in Fig. 5c. $\mathrm{Al}_{2} \mathrm{O}_{3}$ signal was weak for its low content or the formation of part amorphous phases. ${ }^{10,21} \mathrm{~N}$ element was transformed to $\mathrm{N}_{2}$ and evaporated. The following reaction could be proposed..$^{22}$ 

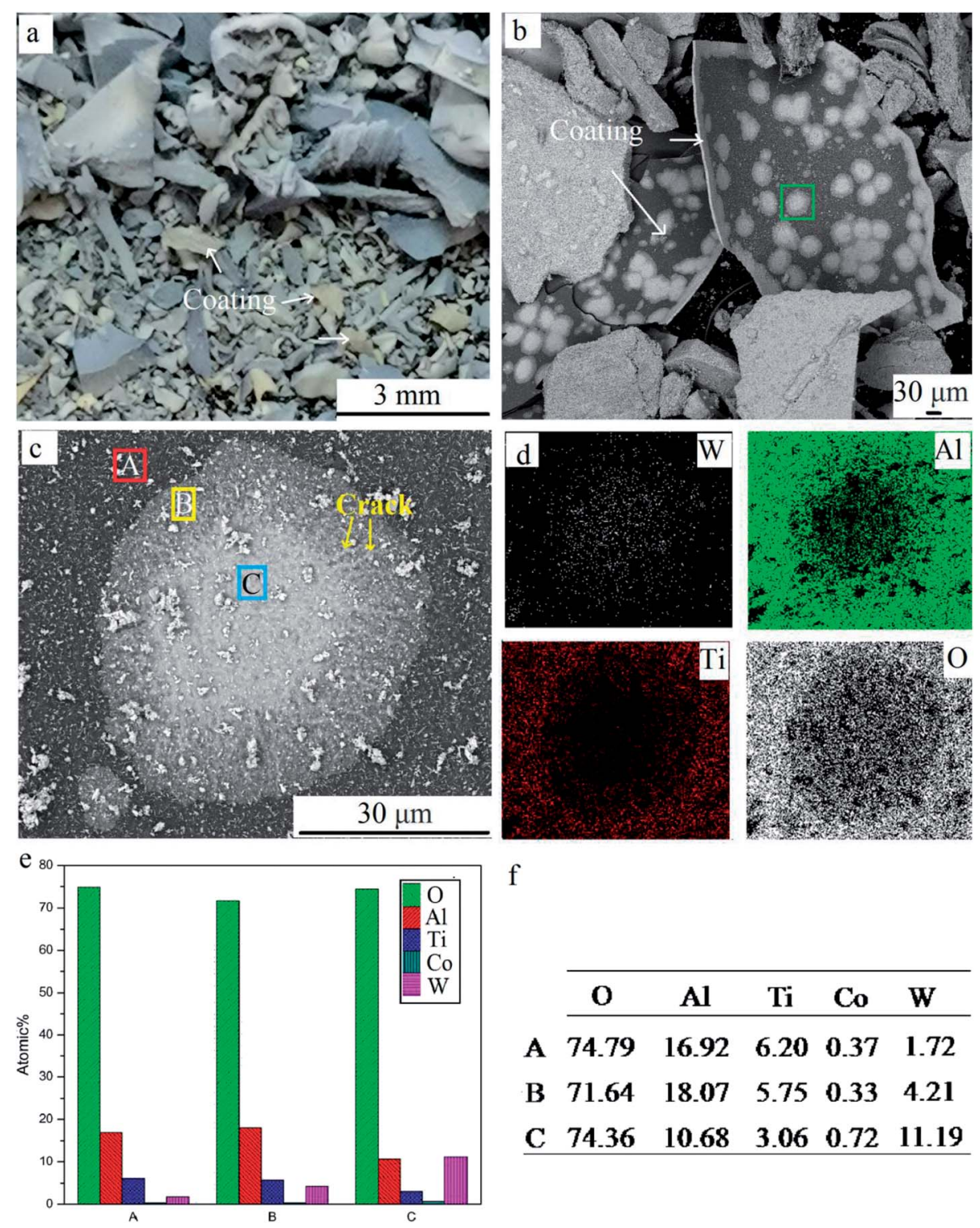

$\mathrm{f}$

\begin{tabular}{lllll}
\hline O & Al & Ti & Co & W \\
\hline
\end{tabular}
$\begin{array}{llllll}\text { A } & 74.79 & 16.92 & 6.20 & 0.37 & 1.72\end{array}$
$\begin{array}{llllll}\text { B } & 71.64 & 18.07 & 5.75 & 0.33 & 4.21\end{array}$
$\begin{array}{llllll}\text { C } & 74.36 & 10.68 & 3.06 & 0.72 & 11.19\end{array}$

Fig. 8 Coatings delaminated from the whole inserts. (a) Macrographs; (b) SEM image; (c) high magnification SEM image; and (d-f) EDS results of three points.

$2 \mathrm{Ti}_{1-x} \mathrm{Al}_{x} \mathrm{~N}_{y}+(2-x / 2) \mathrm{O}_{2} \rightarrow 2(1-x) \mathrm{TiO}_{2}+x \mathrm{Al}_{2} \mathrm{O}_{3}+y \mathrm{~N}_{2} \uparrow(4)$

It is clear that $\mathrm{Al}_{2} \mathrm{O}_{3}$ is not easily decomposed or reactive with others under normal condition. It would be the defect, leading to the bad performance of recycled hard alloys. Consequently, $\mathrm{Al}_{2} \mathrm{O}_{3}$ poses a big problem for recycling coated hardmetal scraps. ${ }^{15}$ Therefore, reducing the negative impact will be the focus of our future work.

\subsection{Evolution of coatings}

Fig. 7 shows SEM images of surfaces at different oxidation times, and Fig. 7a presents the TiAlN coating before oxidation. Pits are visible on the coating, which appeared due to mechanical hitting or stress during the cutting operation. When oxidized for $10 \mathrm{~min}$, more pits and micro-cracks were found. White particles were filled in pits or distributed along cracks, whereas the unbroken coating surface remained smooth, demonstrating that the coating was protective and inhibited elements diffusion. According to the diffusion theory, atoms diffused according to the diffusion coefficient $D$, which can be expressed as follows:

$$
D=D_{0} \exp (-Q / R T)
$$

where $T$ is temperature (K), $R$ is the gas constant, and $D_{0}$ is the value of the diffusion coefficient when $1 / T=0$. The above three were constants for a given system at the same temperature. $Q$ is activation energy $\left(\mathrm{cal} \mathrm{mol}^{-1}\right)$. The lattice is partly distorted and forms irregular arrangement around defects, resulting in a lower $Q$ value compared to the intact parts, thus then obtained a higher diffusion coefficient and lower diffusion resistance. Consequently, defects provide a fast diffusion channel. Both 

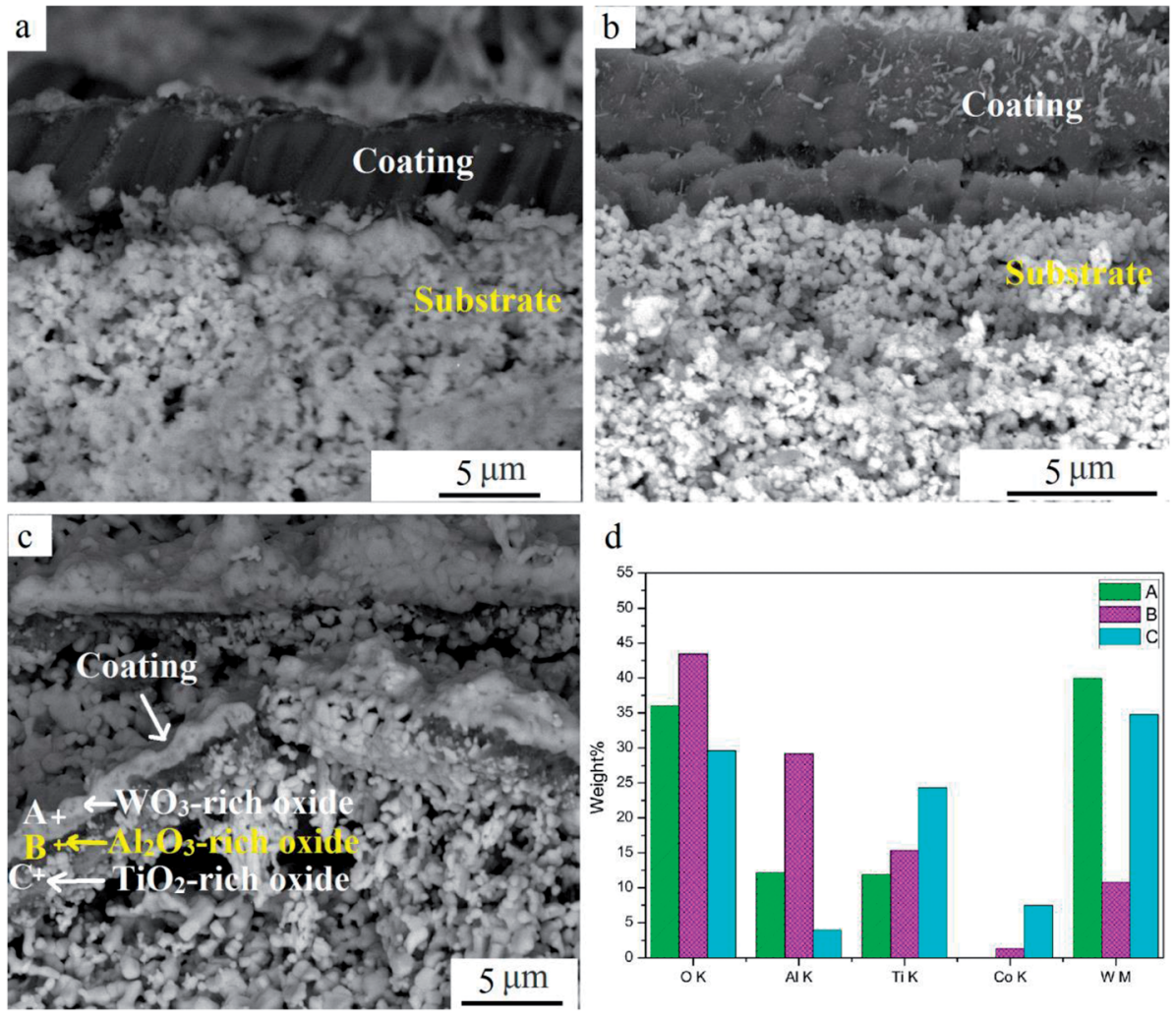

Fig. 9 SEM cross-section images of samples at various oxidation times: (a) $10 \mathrm{~min}$, (b) $60 \mathrm{~min}$, (c) 240 min, and (d) EDS result of points.

outward diffusion of $\mathrm{W}$ and inward diffusion of $\mathrm{O}$ were mainly passed through defects. With further oxidation, more cracks and pits can be seen clearly. During oxidation, the main reasons for defects were stress, porous oxide scales, and chemicals volatilization. When oxidized for $120 \mathrm{~min}$, a number of white particles can be seen on the surface. The EDS results revealed the presence of $\mathrm{W}, \mathrm{O}$, and Co elements in the white chemical, indicating the formation of a $\mathrm{WO}_{3}$ and $\mathrm{CoWO}_{4}$ mixture according to the XRD patterns in Fig. 6a. The magnified image on the upper right hand corner in Fig. 7d, clearly demonstrates the presence of white chemicals concentrated on defectdominated regions, confirming that the defect was the main elements' diffusion track. It is speculated that the oxidation rate accelerates with pre-treatment for more defects, such as shot blasting and quenching.

Unfragmented inserts were further oxidized for $240 \mathrm{~min}$ to study the elements' distribution in detail, as shown in Fig. 8. Pieces of coating were stripped off the substrate (Fig. $8 \mathrm{a}$ and b). On the coating's surface, the pitting like area was visible. There were three distinct regions, the gray area $\mathrm{A}$, the white-gray area $\mathrm{B}$, and the white area C (Fig. 8c), due to the different contents of white $\mathrm{WO}_{3}$. The EDS results show that the content of $\mathrm{O}$ in all areas was high, suggesting oxide scale formation..$^{10}$ The results also showed that the atomic ratio of $\mathrm{W}$ element was highest at point $\mathrm{C}, \sim 2.6$ times that at point $\mathrm{B}$ and 6.5 times that at point $\mathrm{A}$. The significant differential distribution of $\mathrm{W}$ can be attributed to rapid element diffusion through defects, uneven distribution of defects, and considerable volatility of $\mathrm{WO}_{3}$ at $900{ }^{\circ} \mathrm{C}$. It is well known that defects provide preferential pathways for element diffusion, as diffusion coefficient $D$ is higher. Thus the outward diffusion of $\mathrm{W}$ was mainly via defects such as pits and cracks. Meanwhile, $\mathrm{WO}_{3}$ was notably volatile above $850{ }^{\circ} \mathrm{C}$. A small quantity of $\mathrm{WO}_{3}$ in the substrate evaporated via through-wall cracks and deposited on the surface. As shown in Fig. 8c, area $\mathrm{C}$ was filed with white chemicals. Cracks and pits were clearly visible in this area. It was speculated that $\mathrm{C}$ was the defects concentrated area. Fewer obvious cracks can be found in region $\mathrm{A}$ and the concentration of $\mathrm{W}$ was lowest in this area. It confirms that the defect provides preferential pathways for W outward diffusion. Defects on coatings were related to the mechanical damage during the repeated operation before discarded, the stress presented for different thermal expansion coefficients when heated, and porous oxide such as $\mathrm{TiO}_{2} \cdot{ }^{17,19}$ Furthermore, element distribution demonstrated that $\mathrm{Al}$ content was higher than that of $\mathrm{Ti}$ in respective areas, indicating more $\mathrm{Al}_{2} \mathrm{O}_{3}$ on the outmost surface compared to $\mathrm{TiO}_{2}$. This is attributed to the greater affinity of aluminum for oxygen than titanium.

Fig. 9 shows cross-sectional SEM images at different oxidation times. The coating remained dense when oxidized for $10 \mathrm{~min}$. Pits and cracks were visible on the coating after oxidation for $60 \mathrm{~min}$ (Fig. 9b). With further oxidation for $240 \mathrm{~min}$, coatings were broken mainly for stress when heated. ${ }^{16}$ A triple-layer structure can be seen in Fig. 9c. EDS results illustrated that $O$ content was high in all points (Fig. 9d). According to the XRD result in Fig. 6, the layers mainly contained oxides. $\mathrm{W}, \mathrm{Al}$, and Ti contents were highest at points $\mathrm{A}, \mathrm{B}$, and $\mathrm{C}$, respectively. $\mathrm{W}$ and Co contents at point $\mathrm{C}$ were both 
relatively high because the inner coating was in close proximity to the substrate. This implied that the triple-layered oxide scale mainly consisted of a $\mathrm{WO}_{3}$-dominated outmost layer, $\mathrm{Al}_{2} \mathrm{O}_{3}$ dominated middle layer, and $\mathrm{TiO}_{2}$-dominated inner layer. This is different from the bilayered $\mathrm{Al}_{2} \mathrm{O}_{3} / \mathrm{TiO}_{2}$ oxide scale that results during oxidation resistance tests for new TiAlN-coated hardmetals. ${ }^{23}$ The surface $\mathrm{Al}_{2} \mathrm{O}_{3}$ scale was protective and retarded further oxidation in the substrate. Compared to new coated hardmetal, many defects were presented in worn inserts during hitting operation. They provided preferred diffusion pathways, resulting in more $\mathrm{W}$ outward diffusion to surfaces. In addition, $\mathrm{WO}_{3}$ distribution on the outmost layer contributed to its volatilization and deposition at $900{ }^{\circ} \mathrm{C}$. This result indicated that $\mathrm{WO}_{3}, \mathrm{Al}_{2} \mathrm{O}_{3}$, and $\mathrm{TiO}_{2}$ were mixed together in the final oxide scale, and this it was impossible to separate $\mathrm{Al}_{2} \mathrm{O}_{3}$. It has been proposed to transform $\mathrm{Al}_{2} \mathrm{O}_{3}$ into other chemicals or use it as the reinforcement phase for reducing negative effect. We aim to address this process in our future publication.

\section{Conclusions}

In this study, we investigated the isothermal oxidation of WCCo cemented carbide inserts covered with TiAlN coating. Time dependence of the weight ratio for milled powders below $0.15 \mathrm{~mm}$ showed parabolic-like behavior. Milled powders were totally oxidized to a mixture of $\mathrm{WO}_{3}$ and $\mathrm{CoWO}_{4}$ in $180 \mathrm{~min}$. Pieces of coatings can be found in the final oxide. The TiAlN coating was finally transformed to $\mathrm{Al}_{2} \mathrm{O}_{3}$ and $\mathrm{TiO}_{2}$.

During oxidation, the coating was protective and caused retarded element diffusion. Oxidation began on the inserts' edges and corners, where defects were concentrated. Defects appeared and promoted due to the repeated cutting operation, stress, and chemicals volatilization. More cracks and pits were found in W-rich regions as oxidation time increased, since the defects provide a fast track for diffusion. It can be speculated that oxidation rates accelerate as more defects are pre-treated, such as shot blasting and quenching.

There were three distinct layers in the oxide scale, comprised of a $\mathrm{WO}_{3}$-dominated outmost layer, an $\mathrm{Al}_{2} \mathrm{O}_{3}$-dominated middle layer, and a $\mathrm{TiO}_{2}$-dominated inner layer. Consequently, $\mathrm{Al}_{2} \mathrm{O}_{3}$ is difficult to separate alone. Future work will focus on the reduction of $\mathrm{Al}_{2} \mathrm{O}_{3}$ 's harmful influences, or even transform it to behave as the reinforcement phase for improving recycled hardmetals.

\section{Conflicts of interest}

The authors declare no conflict of interest.

\section{Acknowledgements}

This research was funded by the National High-tech Research and Development Program of China (No. 2012AA061902), the
National Natural Science Foundation of China (No. 51564036 and 50904035), and the National Key Technology Research and Development Program of China (No. 2011BAC10B04).

\section{References}

1 T. IshIda, T. ITakura, H. MorIguchI and A. Ikegaya, SEI Tech. Rev., 2012, 75, 38-46.

2 I. Konyanshin, et al., US20180274065A1, 2018.

3 K. J. Brookes, Met. Powder Rep., 2014, 69, 24-30.

4 S. Kim, B. Seo and S. Son, Hydrometallurgy, 2014, 143, 28-33.

5 W. Gu, Y. S. Jeong, K. Kim, J. Kim, S. Son and S. Kim, J. Mater. Process. Technol., 2012, 212, 1250-1256.

6 H. Kuang, D. Q. Tan, W. He, X. R. Wang, J. Zhong, H. J. Wang and C. H. Yang, Mater. Tehnol., 2017, 51, 997-1003.

7 Z. M. Chai, Y. H. Liu, X. C. Lu and D. N. He, RSC Adv., 2014, 4, 51047-51054.

8 C. W. Kim and K. H. Kim, Thin Solid Films, 1997, 307, 113119.

9 Z. Zhou, W. M. Rainforth, C. Rodenburg, N. C. Hyatt, D. B. Lewis and P. E. Hovsepian, Metall. Mater. Trans. A, 2007, 38, 2464-2478.

10 Z. T. Wu, P. Sun, Z. B. Qi, B. B. Wei and Z. C. Wang, Vacuum, 2017, 135, 34-43.

11 C. M. Koller, R. Hollerweger, C. Sabitzer, R. Rachbauer, S. Kolozsvári, J. Paulitsch and P. H. Mayrhofer, Surf. Coat. Technol., 2014, 259, 599-607.

12 B. Grossmann, N. Schalk, C. Czettl, M. Pohler and C. Mitterer, Surf. Coat. Technol., 2017, 309, 687-693.

13 E. Aschauer, S. Sackl, T. Schachinger, H. Bolvardi, M. Arndt, P. Polcik, H. Riedl and P. H. Mayrhofer, Surf. Coat. Technol., 2018, 349, 480-487.

14 T. Chen, Z. W. Xie, F. Gong, Z. Z. Luo and Z. Yang, Appl. Surf. Sci., 2014, 314, 735-745.

15 H. B. Zhu, X. Yang, D. Q. Tan, Y. L. Li, W. He and B. B. Tang, Powder Metall. Mater. Sci. Eng., 2016, 21, 202-208.

16 M. Tkadletz, N. Schalk, R. Daniel, J. Keckes, C. Czettl and C. Mitterer, Surf. Coat. Technol., 2016, 285, 31-46.

17 H. Kuang, D. Q. Tan, W. He, Z. H. Zhou and X. R. Wang, Materials, 2018, 11, 1796.

18 W. Jung, J. Ind. Eng. Chem., 2014, 20, 2384-2388.

19 F. Lofaj and Y. S. Kaganovskii, J. Mater. Sci., 1995, 30, 18111817.

20 B. X. Liu, A. H. Shi, G. L. Yang, Q. Su, G. G. Chen, L. N. Zhang and B. Yang, Int. J. Refract. Met. Hard Mater., 2017, 67, 74-81.

21 B. J. Xiao, H. X. Li, H. J. Mei, W. Dai, F. Zuo, Z. T. Wu and Q. M. Wang, Surf. Coat. Technol., 2018, 333, 229-237.

22 P. Panjan, B. Navinšek, M. Čekada and A. Zalar, Vacuum, 1999, 53, 127-131.

23 K. Lee, S. Seo and K. Lee, Scr. Mater., 2005, 52, 445-448. 